\title{
PREDILEKSI DAN PERUBAHAN PATOLOGI ANATOMI PADA IKAN MASKOKI (Carassius auratus) AKIBAT INFESTASI Lernaea cyprinacea DI KABUPATEN TULUNGAGUNG
}

\section{PREDILECTION AND ANATOMICAL PATHOLOGY CHANGES IN GOLDFISH (Carassius auratus) DUE TO Lernaea cyprinacea INFESTATION IN TULUNGAGUNG}

\author{
Kismiyati, Nadia Ayu Fadila Asshaufi dan Hari Suprapto \\ Fakultas Perikanan dan Kelautan Universitas Airlangga \\ Kampus C Mulyorejo - Surabaya, 60115 Telp. 031-5911451
}

\begin{abstract}
Goldfish (Carassius auratus) is one of the most popular freshwater fish, therefore they has a very great potential market. Increased effort in Goldfish (Carassius auratus) aquaculture industry, fish farmer also faced greater problems. One of it is disease caused by ectoparacites Lernaea cyprinacea. The predilection of Lernaea cyprinacea can be be directly visible, by the presence of parasites attached to the body surface, fins, gills, eyes and mouth of fish. Lernaea cyprinacea attack on fish can cause pathological change such as lesions and nodules on the skin and fins.

This research was conducted in March-November 2013. Location of sampling conducted in Tulungagung East Java while Goldfish (Carassius auratus) pathological examination in the Laboratory of Faculty of Fisheries and Marine Airlangga University. The purpose of this study was to determine the predilection of Lernaea cyprinacea that mostly infested on Goldfish (Carassius auratus) and knowing the change of anatomical pathology in Goldfish (Carassius auratus) infested by Lernaea cyprinacea. The method used was a survey method with random sampling technique and change in anatomic pathology described by the scoring method.

The result showed that the predilection of Lernaea cyprinacea mostly infested on Goldfish (Carassius auratus) on dorsal and caudal fin, anatomic pathology changes on Goldfish (Carassius auratus) that infested by Lernaea cyprinacea are abscess, haemorhage, laceration, and fins damaged
\end{abstract}

Keywords : Predilection, Anatomical Pathology, Goldfish (Carassius auratus), Lernaea cyprinacea

\section{Pendahuluan}

Usaha budidaya ikan hias air tawar mempunyai prospek yang cukup baik untuk dikembangkan. Ikan Maskoki dipilih karena sangat popular, oleh karena kepopulerannya maka ikan ini mempunyai potensi pasar yang sangat besar, baik untuk pasar lokal maupun untuk ekspor (Basuki dkk, 2005). Meningkatnya usaha budidaya ikan Maskoki, tantangan yang dihadapi pembudidaya juga semakin besar. Salah satu kendala yang perlu mendapat perhatian penting adalah adanya serangan penyakit.

Penyakit yang menyerang ikan dapat dibagi menjadi dua, yaitu penyakit infeksius dan non infeksius. Salah satu penyakit infeksius adalah parasit. Lernaea cyprinacea adalah salah satu jenis penyakit yang sering menginfestasi ikan Maskoki. Parasit Lernaea cyprinacea menyerang ikan yang ada di aliran sungai, biasanya hanya menyebabkan kerusakan yang kecil, tetapi apabila pada lingkungan yang tertutup, tingkat serangannya sangat berat dan parah (Demarre, 1967).
Predileksi dapat dilihat secara kasat mata dengan adanya parasit yang menempel pada seluruh permukaan tubuh, sirip, insang, mata, dan bagian mulut ikan (Piasecki et al., 2004). Dampak yang terjadi pada ikan yang terinfestasi Lernaea menimbulkan gejala klinis dan perubahan patologi (Tambunan dkk., 2011). Ikan yang terinfestasi menimbulkan gejala klinis yaitu menjadi tidak aktif, berat badan menurun, stress dan mengalami perubahan patologi anatomi yaitu luka, inflamasi dan nodul pada kulit dan sirip (Amina and El-Mansy, 2009).

Secara alami ikan Maskoki mempunyai habitat kolam berlumpur, bendungan dan sungai (Martiadi, 2002). Ikan ini merupakan hewan omnivora. ikan Maskoki (Carrasius auratus) dapat bertahan hidup di air berkualitas buruk, walaupun demikian kualitas air penting diperhatikan agar pertumbuhan, reproduksi dan kesehatan ikan berjalan optimal (Watson et al., 2004).

Lernaea cyprinacea adalah salah satu parasit yang menyebabkan penyakit pada ikan. Parasit ini hidup pada air tawar dan dikenal 
dengan sebutan anchor worm karena bagian kepalanya berkembang seperti jangkar di bawah kulit ikan (Tambunan dkk., 2011). Bagian tubuh yang berada di dalam tubuh inang berperan untuk mengambil nutrien, sedangkan bagian tubuh yang berada di luar, termasuk kantung telur berperan untuk salah satunya bereproduksi. Kantung yang berada di luar tubuh tersebut memudahkan parasit ini melepaskan telurnya ke air (Alifuddin, 2003)

Lernaeosis merupakan penyakit yang disebabkan oleh ektoparasit Lernaea yang menyerang berbagai ikan air tawar (Berry et al., 1991). Predileksi dapat dilihat secara kasat mata dengan adanya parasit yang menempel pada seluruh permukaan tubuh, sirip, insang, mata, dan bagian mulut ikan (Piasecki et al., 2004).

Ikan yang terinfestasi menjadi diam/tidak aktif, berat badan menurun dengan kerusakan parah terutama pada dasar sirip. ikan juga tampak stress dan berhenti makan (Amina and El-Mansy, 2009). Luka yang diakibatkan penetrasi Lernaea betina dapat menyebabkan pendarahan dan nekrosis pada daerah dimana parasit ini berpenetrasi (Bruno et al., 2003).

\section{Materi dan Metode}

Pengambilan Sampel Ikan Maskoki

Sampel ikan Maskoki diambil pada tiga desa meliputi desa Karang Rejo, Plosokandang, dan Wajak yang berada di Tulungagung, Jawa Timur dengan dua kolam untuk masing-masing desa. Sampel ikan diambil secara acak (random sampling). Menurut Barreiro and Albandoz (2001) jumlah ikan sampel yang diambil sebesar $10 \%$ dari total populasi ikan pada tiap kolam yang dilakukan secara acak. sampel dimasukkan ke dalam plastik dan diberi oksigen lalu dibawa ke Laboratorium Pendidikan Fakultas Perikanan dan Kelautan Universitas Airlangga, Surabaya.

Pengukuran kualitas air

Pengukuran parameter kualitas air dilakukan bersamaan dengan pengambilan sampel ikan pada masing-masing kolam. Parameter kualitas air yang diukur adalah suhu air, $\mathrm{pH}$, amoniak, dan DO.

\section{Pemeriksaan Parasit}

Sampel ikan Maskoki diukur panjang tubuhnya. Ikan Maskoki yang negatif dipisahkan dengan ikan Maskoki yang positif terinfestasi Lernaea cyprinacea. Ikan Maskoki yang positif terinfestasi Lernaea cyprinacea diamati predileksi dan perubahan patologi anatominya.
Pengamatan predileksi

Pengamatan predileksi Lernaea cyprinacea pada ikan Maskoki dilakukan secara makroskopis. Letak infestasi Lernaea cyprinacea pada kulit ikan dan sirip ikan Maskoki meliputi sirip dorsal, pectoral, anal, dan pelvic. Hasil pengamatan disajikan dalam bentuk tabel.

Pemeriksaan Patologi Anatomi

Pemeriksaan patologi anatomi sampel ikan Maskoki dilakukan dengan mengamati perubahan struktur dan tampilan organ (insang, mulut, kulit, dan sirip) yang telah terinfestasi Lernaea cyprinacea. Pemeriksaan patologi anatomi meliputi gejala klinis pada kulit ikan Maskoki pada daerah yang terinfestasi Lernaea cyprinacea. Perubahan patologi anatomi disajikan dengan gambar sedangkan data dideskripsikan dengan menggunakan metode skoring.

Analisis Data

Data disajikan secara deskriptif dalam bentuk tabel dan gambar. Data hasil predileksi dianalisis menggunakan perhitungan frekuensi sedangkan data hasil perubahan patologi anatomi yang diperoleh dianalisis menggunakan uji Kruskal Wallis.

\section{Hasil dan Pembahasan}

Predileksi L. cyprinacea pada Ikan Maskoki di Kabupaten Tulungagung menunjukkan dari 28 ekor pada sirip caudal, 6 ekor pada sirip pectoral, 30 ekor pada sirip dorsal, 17 ekor pada sirip anal, satu ekor pada mata, dan dua ekor pada kulit. Predileksi paling jarang terdapat pada sirip ventral, mata, kulit, dan sirip pectoral, predileksi sedang terdapat pada sirip pectoral dan sirip anal, sedangkan predileksi paling sering terdapat pada sirip caudal dan sirip dorsal.

Hasil pengamatan menunjukkan ikan Maskoki yang positif terinfestasi L. cyprinacea ditemukan perubahan patologi anatomi antara lain abses, hemoragi, laserasi, dan sirip geripis. Hasil penelitian pengambilan sampel ikan dari tiga Desa didapatkan rata-rata ranking yaitu Desa (A) Karang Rejo 24,119, Desa (B) Ploso Kandang 23 dan Desa (C) Wajak 25,35. Ranking di analisis dengan Kruksal Wallis didapatkan H sebesar 1,501795, sehingga tidak terdapat perbedaan signifikan nilai skoring diantara tiga desa.

Pengukuran kualitas air pada saat pengambilan sampel pada tiga desa di Tulungagung menunjukkan bahwa kondisi kualitas air pada kolam ikan Maskoki adalah dalam kondisi normal, namun pada suhu terjadi peningkatan derajat. Data pengukuran kualitas 


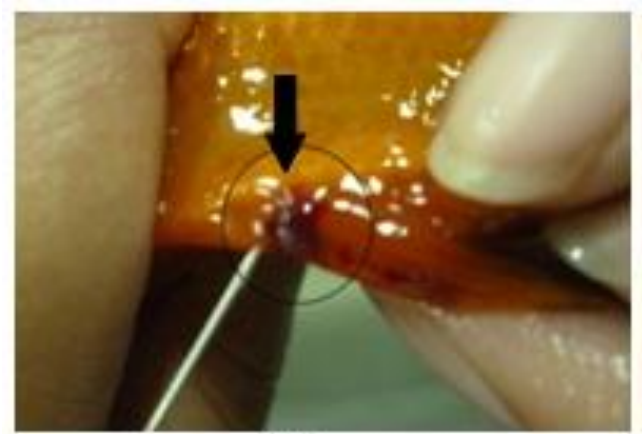

(a)

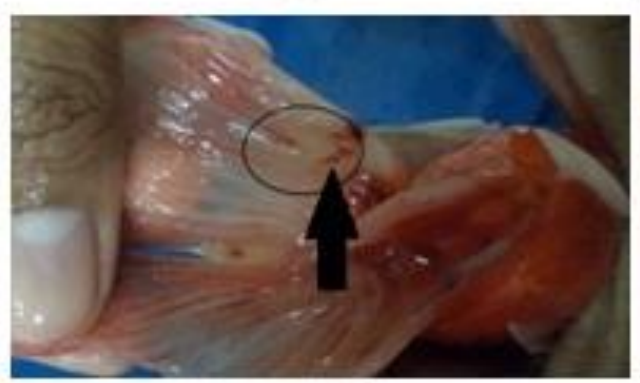

(c)

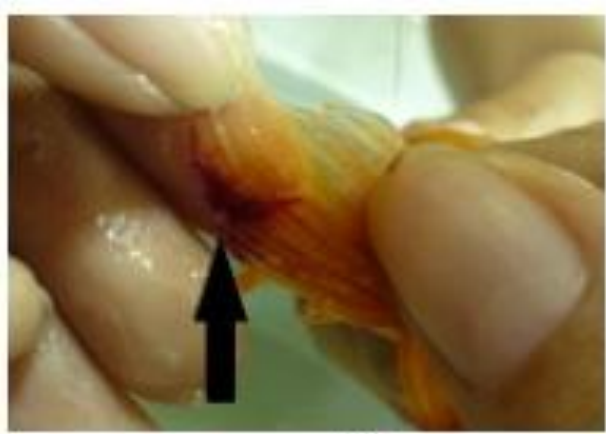

(b)

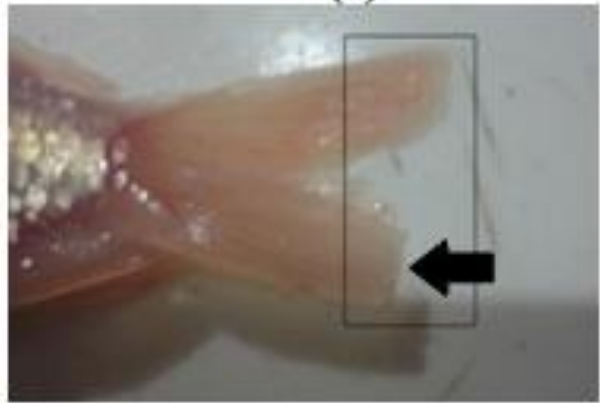

(d)

Gambar 1. Perubahan patologi anatomi pada Ikan Maskoki (anak panah)

Keterangan: (a) Abses, (b) Hemoragi, (c) Laserasi, (d) Geripis

air menunjukkan bahwa suhu rata-rata kolam $29,3{ }^{\circ} \mathrm{C}, \mathrm{pH} 7$, amoniak $0,3 \mathrm{mg} / \mathrm{l}$ dan DO 6,3 $\mathrm{mg} / \mathrm{l}$.

Predileksi L. cyprinacea pada ikan Maskoki paling sering terdapat pada sirip caudal lalu diikuti oleh sirip dorsal. Hal tersebut kemungkinan disebabkan pada sirip dorsal mengalami pergerakan yang kurang aktif daripada sirip lainnya, sedangkan pada sirip caudal ditemukannya parasit pada sisi dalam sirip caudal sehingga kemungkinan untuk kontak langsung dengan arus air lebih sedikit. Hal tersebut didukung oleh penelitian Medeiros and Maltchik (1999) bahwa tingkat predileksi $L$. cyprinacea lebih tinggi pada sirip dorsal, dikarenakan L. cyprinacea lebih memilih lokasi yang memiliki perlindungan lebih besar terhadap arus air.

Predileksi L. cyprinacea yang paling banyak terdapat pada sirip, hal ini disebabkan karena sirip merupakan bagian tubuh ikan Maskoki yang tipis dan memudahkan $L$. cyprinacea untuk menancapkan holdfast nya (Sari, 2010). Sedangkan pada kulit dan mata lebih sedikit jumlah infestasinya, karena lapisannya lebih tebal sehingga $L$. cyprinacea sulit untuk menancapkan holdfast-nya (Sari, 2010).
Berdasarkan hasil pengamatan patologi anatomi ikan Maskoki yang terserang $L$. cyprinacea ditemukan adanya kerusakan yang berupa abses, hemoragi, laserasi, dan kerusakan sirip. Hal tersebut seperti yang dikemukakan oleh Piasecki et al. (2004), dampak yang terjadi pada ikan yang terserang $L$. cyprinacea menimbulkan gejala klinis dan perubahan patologi. Mekanisme serangan L. cyprinacea pada inang dengan cara menusukkan holdfast pada organ target. Tusukan tersebut menyebabkan adanya perubahan patologi anatomi kulit ikan (Berry et al., 1991).

Perubahan patologi anatomi $L$. cyprinacea dilihat dari rata-rata ranking setiap desa menunjukkan tingkat kerusakan paling ringan terletak pada Desa B, selanjutnya Desa A lalu Desa C. Variasi tingkat infestasi $L$. cyprinacea ini dapat dikarenakan $L$. cyprinacea pada saat pengambilan sampel masih dalam tahap copepodid yang belum menempel pada tubuh inang atau dapat juga telah mengalami kematian dan lepas dari tubuh inang, sehingga hanya sedikit ditemukan tingkat infestasi berat. Berdasarkan uji Kruksal Wallis, dapat disimpulkan bahwa tidak terdapat perbedaan yang signifikan diantara tiga desa tersebut. Hal tersebut dapat dikarenakan ketiga desa 
menggunakan teknik budidaya yang sama dan kondisi lingkungan yang tidak jauh berbeda. Infestasi $L$. cyprinacea pada ikan Maskoki sangat dipengaruhi oleh kondisi kualitas air yang digunakan sebagai media budidaya, karena pada kualitas air yang yang buruk infetasi parasit semakin tinggi Dilihat dari nilai kualitas air yang terdapat pada Lampiran 4, kualitas air berada pada kondisi normal dengan suhu tinggi yang sesuai untuk pertumbuhan $L$. cyprinacea. Rata-rata suhu pada kolam sampel yaitu $29,3{ }^{\circ} \mathrm{C}$ yang sesuai dengan pernyataan Amina and El-Mansy (2009) bahwa $L$. cyprinacea berkembang pada suhu $20-30{ }^{\circ} \mathrm{C}$ dan tidak bereproduksi kurang dari $14{ }^{\circ} \mathrm{C}$.

\section{Kesimpulan}

Berdasarkan hasil analisis dan pembahasan dalam penelitian ini, dapat disimpulkan sebagai berikut: Predileksi Lernaea cyprinacea yang paling sering menginfestasi ikan Maskoki (Carassius auratus) adalah sirip dorsal dan sirip caudal. Sedangkan perubahan patologi anatomi ikan Maskoki (Carassius auratus) yang terinfestasi Lernaea cyprinacea adalah abses, hemoragi, laserasi, dan sirip geripis.

Diperlukan penelitian mengenai infestasi Lernaea cyprinacea pada skala laboratoris sehingga dapat diketahui perubahan patologi sesuai dengan lamanya waktu infestasi.

\section{Daftar Pustaka}

Amina, I. and El-Mansy. 2009. On the Occurrence of Adult Females of Lernaea Species (Crustacea: Copepoda) Parasitic on Goldfish Carassius auratus (Linnaeus) in Some Commercial Aquaria in Egypt. Egypt J. Aquatic Biolo. Fish., 13(1): 7 - 36.

Barreiro, P. L. and J. P. Albandoz. 2001. Management Mathematics for European Schools: Population and Sample. Sampling Technique. The University of Seville. 19 p.

Basuki, F., N. Widyorini dan A. Sulistiono. 2005. Memperbaiki Kuantitas dan Kualitas Ikan Hias Mas Koki Lokal (Carassius auratus) Melalui Efisiensi Teknik Reproduksi Dan Seleksi. Laporan Akhir. Universitas Diponegoro. Semarang. 52 hal.

Berry, C. R., G. J. Babey and T. Shrader. 1991. Effect of Lernaea cyprinacea (Crustacea: Copepoda) on Stocked Rainbow Trout (Onchorhynchus mykiss). Journal of Wildlife Disease, 27 (2):206-213.
Demarre Jr. R. S. 1967. Ecology and External Morfology of Lernaea cyprinacea. Departement of Life Sciences. Indiana State University. American Midland Naturalist. 416-427.

Medeiros, E. S. F. and Maltchik. L. 1999. The effects of hydrological disturbance on the intensity of infestation of Lernaea cyprinacea in an intermittent stream fish community. Journal of Arid Environments 43: 351-356

Piasecki, W., A. E. Goodwin, J. C. Eiras and B. F. Nowak. 2004. Importance of Copepoda in Freshwater Aquaculture. Zoological Studies 43 (2) : 193-205.

Sari, P.D.W. 2010. Perubahan Patologi Kulit Ikan Gurami (Osphronemu gouramy) akibat infestasi Lernaea cyprinacea pada derajat infestasi yang berbeda. Skripsi. Universitas Airlangga. Surabaya.

Tambunan, J. E., G. Mahasri dan S. Koesdarto. 2011. Infestasi Ektoparasit Lernaea sebagai Faktor Pemicu Munculnya Infeksi Bakteri Aeromonas pada Benih Ikan Mas (Cyprinus Carpio L.). Universitas Airlangga. Surabaya. 15 hal. 